San Jose State University

From the SelectedWorks of Laurie A. Drabble

2013

\title{
Advancing Trauma-Informed Systems Change in a Family Drug Treatment Court Context
}

Laurie A. Drabble, San Jose State University

Shelby Jones, San Jose State University

Vivian Brown

Available at: https://works.bepress.com/laurie_drabble/58/ 
The manuscript following this cover page is an Author's Accepted Manuscript of an article published in the Journal of Social Work Practice in the Addictions, 13: 1-23, 2013. Copyright Taylor \& Francis, available online at: http://www.tandfonline.com/[DOI:

10.1080/1533256X.2012.756341].

The appropriate citation for this manuscript is:

Drabble, L. A., Jones, S. R., and Brown, V. (2013). Advancing Trauma-Informed Systems Change in a Family Drug Treatment Court Context. Journal of Social Work Practice in the Addictions, 13:1-23.

\section{Corresponding Author:}

Laurie Drabble, Associate Professor

San José State University School of Social Work

One Washington Square

San José, CA 95192-0124

(408) 924-5836

laurie.drabble@sjsu.edu

\section{Acknowledgements:}

Planning for this research was supported in part by the Institute for Collaborative Response for Victims of Family Violence, San José State University. 
Advancing Trauma-Informed Systems Change in a Family Drug Treatment Court Context

\begin{abstract}
:
A growing body of literature documents the importance of trauma-informed and trauma-specific services and systems change in both addiction treatment and child welfare fields. The overall aim of this qualitative study was to explore barriers, benefits, and facilitating factors associated with a trauma-informed systems assessment and improvement initiative conducted in the context of a family drug treatment court (FDTC). Semi-structured in-depth interviews with 12 key informants and historical analyses of project documents over a 4-year time span were conducted. Results underscore the relevance of trauma-informed systems change in collaborative contexts designed to address the complex needs of children and families.
\end{abstract}

Keywords: addiction treatment, assessment, collaboration, child welfare, family drug treatment court, systems change, trauma-informed. 


\section{INTRODUCTION}

A growing body of literature documents the importance of addressing trauma in both addiction treatment and child welfare (Hodas, 2006; Ko et al., 2008; McHugo, Caspi, et al., 2005; National Association of State Mental Health Program Directors and National Technical Assistance Center for State Mental Health Planning, 2004; Savage, Quiros, Dodd \& Bonavota, 2007). There is also considerable agreement about the need for addiction treatment, child welfare, and dependency court systems to work collaboratively (Carlson, 2006; Drabble, 2011; Green, Rockhill \& Burrus, 2008; Marsh, Smith, \& Bruni, 2010; U.S. Department of Health and Human Services [USDHHS], 1999; Young, Boles \& Otero, 2007). Collaborative models of practice, such as Family Drug Treatment Courts, appear to be promising in terms of positive outcomes for both parental treatment participation and parent-child reunification (Boles, Young, Moore \& DiPirro, 2007; Carlson, 2006; Green, Furrer, Worcel, Burrus, \& Finigan, 2007; Osterling \& Austin, 2008; Ryan, Marsh, Testa, \& Louderman, 2006; Worcel, Furrer, Green, Burrus, \& Finigan, 2008). However, there is a paucity of literature examining how trauma-informed systems changes might be advanced in a collaborative context, such as Family Drug Treatment Courts.

\section{Importance of Addressing Trauma}

Research indicates that trauma is a defining, reoccurring event in the lives of individuals with both substance abuse and mental health disorders (Najavits, Weiss \& Shaw, 1997; Bryer, Nelson, Miller \& Krol, 1987; Kilpatrick, Acierno, Resnick, Saunders \& Best, 1997). For example, one of the largest, most representative studies examining the long-term effects of trauma, the Adverse Childhood Experiences (ACE) study of over 17,000 women and men, found strong correlations between childhood trauma and long term negative health outcomes, including addiction (Dube, Felitti, Dong, Giles \& Anda, 2003; Felitti et al., 1998). Although treatment services and systems 
have often neglected to address trauma in the lives of adults with co-occurring disorders (Becker et al., 2005; Timko \& Moos, 2002), an emerging body of literature documents the value of integrating a trauma lens in addiction treatment and mental health services. For example, the Women, Co-Occurring Disorders and Violence Study (WCDVS), a quasi-experimental, ninesite, longitudinal study examined the prevalence of trauma among over two-thousand women with co-occurring disorders, as well as outcomes when treatment was integrated (McHugo, Krammerer et al., 2005). Results from the WCDVS found the trauma-informed framework to be a helpful paradigm, not only for understanding the complex issues facing women with cooccurring disorders, but also for improving outcomes (Amaro, Chernoff, Brown, Arévalo \& Gatz, 2007; Becker et al., 2005; McHugo, Caspi et al., 2005; Morrissey, Ellis, et al., 2005; Morrissey, Jackson, et al., 2005; Reed \& Mazelis, 2005; Savage et al., 2007). Although many of the consumers in the WCDVS study were involved in child welfare systems, extension of trauma-informed services and systems change into dependency court contexts were not explored in this body of research.

Research also documents the importance of addressing trauma in childhood, including incorporating the family in treatment (Hodas, 2006; Ko et al., 2008). “Trauma informed care must begin with the provision of safety, both physical and emotional, by adult caregivers to the traumatized child” (Hodas, 2006, p. 32). In addition, research indicates that "families in particular remain the single most important resource for a child dealing with trauma exposure and trauma-related symptoms” (Hodas, 2006, p. 48). Addressing child maltreatment in collaboration with parents through a trauma-informed, strengths-based lens has the potential to reduce future instances of child trauma and keep families together. National studies document that risk factors for child maltreatment are caregiver substance abuse, caregiver exposure to 
domestic violence, and caregiver mental health (National Center for Injury Prevention and Control, 2005). The prevalence of trauma among caregivers with these co-occurring problems indicates that trauma-informed care and systems change is not only important for children's services, but also for services working with parents, such as family drug treatment courts.

\section{Trauma-Informed Systems}

In a trauma-informed system, trauma is not only recognized as an event or series of events in an individual's life span, but as a life-altering experience that can form the "core" of an individual's identity (Harris \& Fallot, 2001). A trauma-informed system is one that "incorporates knowledge about trauma" in every area of its service delivery system, both within an individual system and across systems (Harris \& Fallot, 2001). Developing trauma-informed systems is not easy, as it involves a vital cultural shift. According to Harris \& Fallot (2001), a trauma-informed system must incorporate principles of safety, trustworthiness, choice, collaboration, and empowerment at every level.

Trauma-informed systems are characterized by principles of client choice, empowerment, collaboration, safety and respect, resilience, and the goal to minimize organizational retraumatization (Elliott, Bjelajac, Fallot, Markoff \& Reed, 2005). In addition, Harris \& Fallot (2001) argue that a trauma-informed system must understand not only the trauma history of their clients, but must also consider the larger societal factors contributing to violence and victimization that are common among consumers of mental health and substance abuse services. A trauma-informed system must then use this knowledge to inform the design of the system, including how the system accommodates the vulnerabilities of trauma-survivors as well as how the system incorporates client choice in treatment (Harris \& Fallot, 2001). 
Implementation science provides a framework for considering how organizations and systems engage in a strategic effort to mainstream innovations based on new knowledge and research findings through four essential activities: planning, engaging, executing, and evaluating. (Mildon \& Shlonsky, 2011). Mildon and Shlonsky (2011) argue that passive uptake strategies are insufficient, as they fail to adequately engage practitioners and or address contextual challenges to implementation. There are many strategies involved in becoming a traumainformed system, which are consistent with implementation science. Specific strategies include administrative commitment to change, universal screening for trauma histories among clients, training and education on trauma, hiring practices, and a holistic review of policies and procedures (Harris \& Fallot, 2001). Implementation of organizational and systems change requires consideration of contextual issues, including barriers to change. Some researchers have associated the barriers to recovery from trauma to "organizational stress," or "collective systemic trauma” (Bloom, 2006, p. 25). In some cases, power differentials involved in different systems, such as that between a client and a social worker or judge, can replicate the dynamics of power and control involved in family and community violence. Bloom (2006) stated, "Recovery begins with safety, and without addressing organizational change we fear the recovery movement will not have the impact it must have for true transformational change” (Bloom, 2006, p. 25).

Historically, systems serving individuals with co-occurring disorders (such as trauma, mental health issues, health problems, and substance use disorders) have been characterized by compartmentalization, fragmentation, and a tendency for systems to operate independently from one another (Harris \& Fallot, 2001). Successful collaboration between addiction treatment, child welfare, dependency courts requires development and articulation of shared values; adoption of specific evidence-based practices for children and families; implementation of collaborative 
systems changes (e.g., training, budgeting, and information sharing), and development of shared outcomes (Young \& Gardner, 2002). These dimensions of collaboration are relevant to the integration of trauma-informed systems change in the context of research, which continues to document the importance of trauma as a pivotal connection between service delivery systems and focal point for evidence-based, consumer centered practice (British Columbia Center of Excellence for Women's Health, 2011).

\section{Trauma and the Courts}

FDTCs are specialized courts that operate under the juvenile dependency court system. "These courts provide the setting for a collaborative effort by the court and all the participants in the child protection system to come together in a non-adversarial_setting to determine the individual treatment needs of substance-abusing parents whose children are under the jurisdiction of the dependency court” (Edwards and Ray, 2005, p. 1). FDTC settings provide frequent court hearings and support from a team of representatives from the court, child welfare, substance abuse treatment, and other service providers (Worcel, Furrer, Green, Burrus, \& Finigan, 2008). FDTC models appear to be associated with greater success in treatment and higher reunification rates compared to clients who receive traditional child welfare services (Green et al., 2007; Worcel et. al, 2008).

Perhaps some of the most adversarial systems that trauma survivors may experience are the courts. However, few studies examine explicitly the prevalence and dynamics of trauma in court settings, including collaborative court settings, such as FDTC that are intended to minimize adversarial dynamics. One notable exception to the dearth of research on this topic is a study by Lesperance (2001), which found participants in family drug treatment court $(\mathrm{N}=25)$ reported similar experiences of trauma as that of women in the WCDVS, with a reported average lifetime 
exposure to 12 stressful events, lifetime frequency of 12 different events of interpersonal abuse, and an average frequency of two incidences of childhood physical or sexual abuse. Trauma was also linked to risky behaviors in substance abusing parents (Lesperance, 2001). Similarly, among court-referred youth in the juvenile justice system, studies have found the prevalence of trauma and post-traumatic stress disorder to be up to 75 percent for females and 51.3 percent for males (Brosky \& Lally, 2004). Researchers have recognized the prevalence of family violence among youth and emphasize the importance of strategies to make the court process less adversarial and more supportive of recovery (Buel, 2003; Green, Furrer, Worcel, Burrus, \& Finigan, 2007).

Access to timely substance abuse treatment and efforts to maximize success in treatment for substance use disorders are important to reunification and permanency for children in the child welfare system (U.S. DHHS, 1999). Stringent timelines for reunification mandated by the Adoption and Safe Families Act (ASFA) amplify pressures for courts and partnered service delivery systems to optimize opportunities for successful recovery (Green, Rockhill \& Furrer, 2006; U.S. DHHS, 1997). Despite the prevalence of trauma among clients and the urgency for timely access to effective treatment, few studies examine potential retraumatization of these clients as a result of participation in the court process, and even fewer studies have examined what helps and hinders trauma-informed systems change in court contexts.

The overall aim of this study was to examine the process and outcomes of a traumainformed system assessment conducted within a family drug treatment court. Specific research questions include the following:

1. What were the core strategies associated with the implementation of a trauma-informed assessment process? 
2. What were the benefits, barriers, and facilitating factors related to trauma-informed systems change?

\section{METHODS}

This qualitative study used a combination of semi-structured, in-depth interviews with 12 key informants and historical analysis of project documents over a 4-year time span. The site of study was one cross-system, collaborative family drug treatment court (FDTC) located in a diverse California County, with a population of more than 1,809,000, fifty-eight percent Caucasian, thirty-three percent Asian-American, and twenty-seven percent Hispanic. The project is a collaborative FDTC within the child dependency court system that specifically serves parents with alcohol and other drug use disorders, and who have children under the age of three. The project was one of 53 sites funded to improve outcomes for children impacted by parental substance abuse (see U.S. DHHS, 2010). The goals of the FDTC include early identification of treatment issues, rapid engagement and retention in treatment, and comprehensive, collaborative response from service providers. This study was conducted in collaboration with the FDTC, and implemented by a volunteer research team of faculty and graduate students from a local university.

\section{Sample}

Purposive sampling was employed to recruit interviewees representing the family drug treatment court and partner systems, who were closely involved in collaborative planning and project implementation over the course of the first four years of the project. Key informants were selected from a pool of approximately 40 professionals who were involved in FDTC strategic planning and/or direct implementation based on the following criteria: (a) involvement in FDTC,

(b) inclusion of individuals from different systems, and (c) knowledge of trauma-informed 
systems change efforts in FDTC. The final sample included 12 key informants over the age of 18 , representing the court and legal services $(n=3)$; peer mentor $(n=1)$, drug and alcohol treatment $(n=2)$, child welfare and children's services $(n=3)$, mental health $(n=1)$, domestic violence services $(n=1)$, trauma consultant $(n=1)$.

\section{Interview Guide \& Data Collection Procedures}

Interviews were conducted using a semi-structured interview guide, took approximately 45 - 60 minutes, and were audio taped with the permission of the interviewee. The interview guide was designed to explore research questions based on seven open-ended questions and follow-up probe questions in three broad areas: (a) reflection about the process of, and insights derived from, conducting trauma-informed systems assessments; (b) benefits and barriers related to trauma-informed systems change efforts; and (c) impact and "lessons learned” from participating in trauma-informed systems change efforts. Interviews took place between December 2011 and February 2012. Historical data included bi-annual reports and documents summarizing results of trauma-informed systems assessments. In-depth interviews were transcribed verbatim.

\section{ANALYSIS}

Content analysis of interview transcripts was conducted to identify common themes related to facilitating factors, barriers, and benefits to implementing trauma-informed systems changes. Two authors read a sample of transcripts from respondents representing different systems and independently developed a list of provisional codes, which were reviewed and refined for use as a start list of codes. Initial open coding to conceptualize, compare, and categorize data was followed by an iterative process to further define and identify connections between categories in the data (Strauss, 1987; Strauss \& Corbin, 1990). New codes were developed and existing codes were rearranged or modified throughout the first phase of analysis. Researchers (the first two 
authors) used a consensus model in reviewing, revising and finalizing themes to strengthen trustworthiness of the analysis. The third author was consulted as needed in resolving discrepancies or questions that arose in the analysis process.

Secondary data from project documents and trauma-informed systems assessments previously conducted at FDTC were also analyzed. Historical data included summary documents and attachments from seven semi-annual reports, strategic planning session summaries, and findings of a special FDTC trauma assessment. Data for the semi-annual and special reports were compiled primarily by project staff and consultants, with input and oversight from leaders in partner systems. Data from these documents were analyzed for themes pertaining to core strategies for trauma-informed system improvements and findings of trauma informed system assessment. Data from historical documents were triangulated with data from narrative interviews in order to reduce potential bias and to address potential gaps in the narrative data from in-depth interviews. Preliminary findings were reviewed during a meeting of FDTC system leaders, many of whom were interviewed for the study, to verify the trustworthiness of the findings.

\section{RESULTS}

\section{Core Strategies for Advancing Trauma-Informed Systems Change}

The FDTC identified trauma-informed systems change as a pivotal goal and use of a traumainformed perspective as a core value during the formative months of the project (in 2008). Review of historical FDTC documents, as well as responses from key informants, revealed several intersecting strategies for advancing trauma informed systems changes during the formation and implementation of the project. The prevalence of trauma among program participants was discussed, and the need for trauma-informed systems change was prioritized 
early in the project by a Strategic Planning Team comprised of over 30 leaders and providers across systems (courts; children’s services; mental health; addiction treatment; attorneys; representatives of a mentor parent project; domestic violence service providers; and other partners). Based on interviews and review of historical documents, this section highlights of key strategies and activities that were initiated during the strategic planning process and implemented over the formative years of the project.

One of the pivotal components of the overall strategy involved conducting traumainformed “walk-through” assessments adapted by Dr. Vivian Brown (based on the work of Fallot \& Harris, 2006) as a tool for helping agencies and systems recognize potential trauma triggers within their agency and develop mitigation strategies for addressing change. The assessment includes questions such as whether the facility/system offers a safe place for clients/families; whether screening includes substance use, mental health, and trauma questions; the degree to which clients receive clear explanations and information about program procedures; types of choices clients are given about services; and sensitivity of staff to the potential of retraumatization during certain procedures. In addition to these and other questions, the trauma assessment "walk-through" includes questions related to the system's current status and readiness for change, including questions about administrative support for trauma-informed services and opportunities for trauma training. Review of historical documents as well as responses from interviewees regarding their experience of the trauma-informed "walk-throughs" revealed the assessment's strengths, limitations, and potential for furthering trauma-informed systems change efforts in the courts and partner systems. Some of potential strategies that were identified from the trauma assessments and recorded in the historical documents included: the development of a specialized trauma-informed parenting module; training on trauma and men; training for court 
staff; and development of trauma-informed child activities. All of these were subsequently developed and implemented.

Identification of trauma triggers and action steps. Interviewees who had participated in the assessment process uniformly described the process as effective in surfacing specific potential trauma triggers and generating ideas for reducing or eliminating triggers. "What everyone was asked to do was basically put themselves in the shoes of a client,” noted one participant. One respondent stated, “The training enhanced having an 'eye' towards a traumainformed facility." Other informants commented, "We had good cross participation and great potential action steps came out of it." "We were sobered by the process and then sobered by some of the challenges." "Just the concept of doing a trauma-informed survey reframes everything. It heightens the awareness of what our parents have to go through, and what their kids have to go through.” Examples of triggers described by interviewees and documented in historical documents included crowded waiting rooms that were stressful for children, presence of security personnel, and intimidating court processes and environment. Illustrations of specific strategies for mitigating some of these potential triggers included creation of a space designed for children in the waiting area, provision of training for security personal about trauma and trauma reactions, and improved preparation for parents about what to expect in court.

Exploration of options for change in systems and among providers. Many respondents commented on the "feedback" of the trauma consultant as being particularly helpful throughout the "walk-through." Ideas generated in discussion with the consultant and other participants in the walk through "made sense to the team." The exploration also challenged individuals to examine how they may inadvertently contribute to re-traumatizing clients. One participant observed, "It was helpful to kind of check in with [the consultant] to see, for me, at least my role, 
how I'm communicating with clients, whether, you know, if it's appropriate? Could that be more traumatic, the way that I communicate?”

Flexibility in method of assessment (telephone vs. in-person). The assessment was designed to be flexible for use in various settings, and conducted with a small team (of two to four) individuals. Agencies who participate in the assessment generally do so by physically walking through their agency while considering various practices and procedures. To accommodate schedules of multiple court partners, a virtual "walk-through” was conducted over several telephone meetings with a larger group (8-10 participants). Interviewees who participated in telephone assessment meetings noted that the process was both productive and increased opportunities for participation. Others commented on the challenge of conducting the walk-through over the phone, noting "It was a little constraining... when someone is on the speaker box, it's harder not to talk over somebody else.” However, limitations that were raised did not overshadow the value of the walk-throughs and the important trauma-related issues that were raised and addressed as a result of the assessment.

Parallel processes across partner systems. FDTC historical documents and interviews revealed that the trauma-informed systems assessment served as a strong catalyst for new trauma-informed change initiatives in several partner systems. The assessment process also augmented the work of partner systems that had already initiated similar processes to implement trauma-informed services and systems change within their own agencies. These parallel processes were noted as a positive outcome of the trauma-informed initiative of FDTC.

Training with experts in trauma informed interventions and systems. Historical documents and interviews also reflected the value of trauma-related training designed to support trauma-informed systems changes. Trainings were provided on multiple levels: training with 
direct FDTC providers and court staff, training for all partner systems through interdisciplinary conferences and training, and targeted training for partners on key and emerging topics of interest (e.g., trigger identification and de-escalation strategies, men and trauma, child-specific trauma activities). Partner agencies implemented additional trainings, frequently providing for participation of staff from other service delivery systems. Although interviewees (and historical documents) generally described this constellation of assessment and training activities as strengths, several also highlighted the need for more effective communication and collaboration across systems to maximize benefits across agencies.

\section{Benefits, Barriers \& Facilitating Factors in Trauma-Informed Systems Change}

The benefits, as well as key barriers and facilitating factors in advancing trauma informed systems change, are summarized in Figure 1. Themes in these three over-arching areas were derived primarily from in-depth interviews.

Benefits of trauma-informed systems change. Interview responses regarding the benefits of implementing trauma-informed systems change are described three-fold: (a) increased awareness of trauma, (b) benefits for the clients, and (c) benefits for service providers and systems.

Increased awareness of trauma through adoption of a "trauma lens." Interviewees generally felt positive about the process of undergoing trauma-informed systems change and felt it was helpful in understanding their clients, their histories, and the effects of trauma on their ability to parent and connect with their children. One response typified interviewee comments: "One of the really great things that has come out of this whole process is a much higher level of awareness of trauma and providing trauma-informed, trauma-sensitive services.” Interviewees described the assessment process as invaluable to helping them to operationalize what it means to view service delivery systems and client experiences in court (or partner services) through a 
trauma lens. The phrase, “Think trauma first," came up frequently in interviews as a phrase that helped individuals remember what they learned in the walk-throughs throughout their day-to-day practice. Further, many interviewees commented on the walk-throughs as being a catalyst for a general “culture change” in the community around implementing trauma-informed changes

Benefits for clients. A common response regarding the benefits of implementing traumainformed systems change is that service providers "have a higher level of sensitivity and respect for parents...in part, because of the trauma-informed trainings.” The following quote also typifies comments made by interviewees,

I look at what our parents go through and really try to put ourselves in their shoes and treat each other the way we want to be treated but it also has this vibe of when we try to think about what we do and when we do it and why we do it the way... and it just makes us more aware of how we interact with our parents or how we talk to them or how we ask them to do things. I think the benefits would include that our parents get better services. Respondents further related the success of trauma-based services and systems to the overall evidence supporting strengths-based approaches to service delivery, specifically highlighting the healing that can take place for parents and children alike when trauma is addressed at all levels of treatment,

Not only are we thinking about the trauma of the parent and the child, but also we're steeped in the strength-based approach to recognizing that that parent knows their child best... and to improving ways to affirm that parent in their relationship with their child... and realizing that that can be one of the most healing experiences for the parent as well as the child. The two combined has been very powerful. 
Generally speaking, most interviewees felt that the trauma-informed approach in family drug treatment court made parents feel "heard” and "not judged.” The parents were more likely to engage in the process and more likely to open up in the court setting. One interviewee commented, “I think that people are much more likely to be open and be willing to do what's necessary if they feel safe.”

Benefits for Service Providers and Systems. Benefits for service providers seemed to emerge around ideas of fostering "hope” and "inspiration.” While some staff discussed feeling stressed working in the field of child welfare, drug treatment, trauma, and the courts, respondents noted that trauma-informed systems change contributed to client success which, in turn, directly affected their own job satisfaction. One respondent stated,

I think it gets the parents comfortable with the team. It says, these are my allies, they're not my enemies, they're here to ensure success for me... Because if they see that their court officer is paying attention to them, is interested in what they're saying, and is providing feedback, and if the team is providing feedback based on what they're saying, they become more interested. They buy into it, and they say, “Ok, well maybe this team does know what they're talking about.” So I think those are some of the positive benefits. I mean, there's not a lot of wins in what we do, so it gives you little wins here and there...which give you energy and give you the inspiration and hope that you can keep doing it, because something good is coming from it.

Barriers to implementing trauma-informed systems change. Respondents discussed a number of barriers to implementing trauma-informed systems change that were often related to barriers to systems change and collaboration in general. These barriers are described in the 
following four main areas: (a) physical, functional, and social context, (b) culture, philosophies, and values of different systems, (c) mandates of systems, and (d) systemic stressors.

Physical, functional, and social context. Themes emerged related to the physical, functional, and social environment of courts that are challenging for implementing traumainformed systems change in court contexts. For instance, themes emerged describing the very purpose and history of the court system as one that is adversarial and confrontational in nature. The very experience of entering the courthouse can be triggering for clients. One interviewee from the domestic violence field stated, “... what people experience coming into court, the huge challenges of the physical makeup of the building, in terms of the actual court process, it's overwhelming.”

One participant reflected on the nature of the court as being a "foreign" and unfamiliar place for clients, and therefore, having the potential to be frightening:

There was not a lot of room for confidential conversations, a lot of clients all mixed together. You get called by someone you don't know to come into the courtroom, and there are ten people there. You might know your attorney and your social worker, but certainly the first time you walk in, you're walking into what's basically a foreign land, and it's not particularly welcoming.

Respondents also highlighted inherent triggers about the courts, such as security personnel, police guards, and metal detectors. One interviewee stated, “There are also criminal cases going on in the ground floor," indicating that parents and children appearing at dependency court are inherently going to be passing by individuals in prison garb and handcuffs, furthering feelings of being present in an unfriendly, unsafe environment. 


\section{Culture, philosophies, and values of different systems. "Different philosophical} frameworks, different parameters in terms of ethical and legal obligations" inherent in the traditions and education of different disciplines and systems were noted by respondents as a significant barrier. For instance, many interviewees highlighted the differences in training and education of social workers, clinicians, and treatment providers to that of law enforcement, attorneys, and judges. Trauma-informed systems change, by nature, was described as conflicting with the training of professionals in the legal and law enforcement fields. One respondent wondered, "How do we get law enforcement on the bandwagon?” while others described issues with "the deputies and their attitudes and how they spoke to people." Respondents also described many challenges in working with attorneys who are trained differently than social workers. One respondent noted,

Attorneys are trained, obviously, very differently...I mean, they're very humanistic, but they're attorneys, and it's a different role, so for me, the whole notion of trauma-based services...my problem interfacing with the attorneys is it gets, they haven’t worked with this vicarious trauma.

Other interviewees described barriers related to different value systems present in family drug treatment courts, namely, values of the child welfare, substance abuse, and mental health systems. For example, one respondent commented on differing perceptions about efforts to implement trauma-informed systems changes and practices: "This is not enabling, not codependency. This is sensitivity to trauma survivors... I think this comes from the lack of sensitivity about addiction.” Many other respondents also described the difficulty service providers faced in stretching themselves beyond the traditional roles of their own system while practicing through a collaborative, trauma-informed lens. 
Mandates of systems. Barriers related to legal mandates upon systems were a common theme among participants in this study. In general, interviewees’ responses reflected barriers related to "policies and procedures that will continue to exist always," that partners in the courts must follow and uphold that may or may not be trauma-informed.

One respondent expressed the difficult challenge of implementing trauma-informed systems change in a system that inherently causes additional trauma for both families and children. This interviewee stated,

I think there has always been and continue to be a bit of a conflictual rub between making sure that the legal process and jurisprudence is adhered to and people are served in a client [centered], a trauma-informed way, and the legal process doesn't always facilitate that. And the child welfare process, very rarely do people feel good about removing children and about permanently removing children, and there's no way to make that a non-traumatic experience.

Similarly, some interviewees described tension around making the court safe versus making the court trauma-informed. Many interviewees seemed to struggle with that idea and expressed that that tension was a barrier.

Deputies' obligation is to maintain safety in the court, not just in the courtroom, but throughout the courthouse. Their training is to take charge, to demonstrate that authority is necessary to maintain whatever needs to be maintained for safety, and sometimes that can be done in a very trauma sensitive way, but that's not where the deputies are coming from. And, sometimes if they used a trauma-informed approach, it might not be the right approach because of the circumstances. So, I think that there can be conversations, but we always have to loop back to what are the obligations? 
Other responses highlighted legal mandates on the child welfare system and dependency courts which, at times, conflict with the pace of trauma treatment. This idea was exemplified by the observation that, "the court is time-limited, and not everybody can work on the court's clock...sometimes it's not reasonable to expect people can address these things in the period of time they have.” Legal requirements related to case plans were also noted as a barrier to traumainformed systems change. While some respondents highlighted certain processes, such as "Family Team Meetings," which are geared towards making the case planning process more client-centered, others pointed to tensions around case planning in the context of systems that historically tended toward "cookie cutter” plans that were "lacking sensitivity” to individuals.

Systemic stressors. One final theme that emerged regarding barriers were system stressors inherently faced by social workers, clinicians, attorneys, judges, and all other professionals alike. "There are so many other demands.” These stressors included high case loads and limited funding, resources, and time. At the same time, some responses argued that the nature of trauma-informed systems change is not dependent on funding, typified by the following observation: "The minute you ask somebody to change they always say they need more funding, but you can do this very cheaply. You can really do this without a huge amount of additional funding.”

Other barriers related to resources were frequent staff turn over and training opportunities. One respondent stressed the need for "ongoing discussions and ongoing training” due to the fact that “team members do change.” Another interviewee stated, “....we haven’t had a consistent team, so that contributes to gaps.”

Another prominent theme regarding stressors was the idea of "vicarious trauma." Vicarious trauma was described by most all interviewees as an enormous barrier to 
implementing trauma-informed change in court settings. One interviewee described vicarious trauma as a "systemic thing.” Most interviewees acknowledged that not only are "clients regularly re-traumatized over and over and over again by the system,” but social workers and others working in the system are as well.

Facilitating Factors to Implementing Trauma-Informed Systems Change. Four major themes emerged related to facilitating factors to implementing trauma-informed systems change in the Family Drug Treatment Court, which served to strengthen potential benefits and address barriers: (a) a formal commitment emphasizing ongoing training, walk-throughs, and discussion about trauma-informed changes; (b) trauma champions; (c) support and advocacy through peer mentors; and (d) judicial leadership.

Formal commitment emphasizing ongoing training, walk-through assessments, and discussion about trauma-informed changes. Many respondents stressed the importance and helpfulness of sensing a formal commitment from leaders and partners in their systems towards making trauma-informed changes. This commitment was reflected in "ongoing conversations and honest sharing of concerns.”

We really need to implement that. Everyone has to take it on, every clinic manager, it has to start sort of at the top, with the executive management, senior management, at the management level. It used to be something that, to keep it alive you have to continuously raise it, raise its awareness. Discuss it.

One respondent commented on the role of upper management in implementing traumainformed systems change with personnel who may have less education and training. “Supervisors are able to help the volunteers understand what it's like for a bio-parent to have so much trauma or a child to be part of our program.” Many interviewees mentioned the various 
collaborative team meetings involved in FDTC, from management level collaborative committees to teams involved in implementation, as particularly helpful in the collaboration aspect of implementing trauma-informed systems change.

Interviewees also reflected on the importance of always coming back to the table to discuss trauma-informed changes because of the time required to make these changes: "One [lesson] that we seem to have to learn over and over again is that it takes a long time to change systems...The commitment has to be long term.” Another interviewee emphasized that longterm commitment to training and ongoing discussion aids in bringing in new team members who may not be as familiar with trauma-informed services and systems. "Team members do change...and even for people who are experts, it never hurts to have a refresher and new discussion because you could always learn and think about things you've never thought about before.” Other respondents emphasized the walk-through assessment process as a tool for both training and continued system improvements, including "Just checking and maybe doing periodic surveys, testing the knowledge and assessing all the different sites where there are clients.”

Trauma leaders and champions. "It's extremely important that there are trauma champions. If you don't have the trauma champions, it’s going to be very difficult.” This and other comments describe the need for champions and leaders when implementing traumainformed systems change. One respondent stressed the need to have multiple champions behind trauma-informed systems change since there is frequent staff turnover in the courts, "You never have just one champion within a system. You have to have a number.” Other comments reflected the role that champions play in moving trauma-informed systems change along, for 
instance, "I think we need to have someone championing it. We need to have someone in the department who is taking this on and passing the word and going to meetings.”

Support and advocacy through peer mentors. Interviewees frequently brought up the value of a peer support program (a key program component of the FDTC), which matches clients with mentor parents who are in recovery and have been through the child welfare system, "You just can’t talk trauma-informed without having a [peer mentor] there,” noted one interviewee. Another interviewee stated,

I think the mentors are great as far as working with the parents, them sharing their story, and kind of giving them that encouragement to work, you know, whatever might be traumatizing... to think of other avenues that might be best for the child... Mentors help talk the parent through what might be best for the child.

According to respondents, peer mentors not only help the parents walk through the court process, but also offer them hope. Peer mentors also provide important, needed insights to lawyers, social workers, other officials, and the judge in understanding what the parent goes through as they navigate the system. One interviewee who served in a peer mentor role stated, "We were actually going to do a training for our agency about what we can do differently here from the mentors’ perspectives.” Peer mentors were frequently mentioned as key in implementing trauma-informed systems change because they are the window for the court into the trauma experience of parents and children in family drug treatment courts.

Judicial leadership. One point made consistently across interviews was that of "bench leadership.” One observation echoed across interviews was that the judge, "made it clear from the very beginning that she thought this was important, that most people appearing [in the court] had trauma in their lives and that somehow the court had to address that and acknowledge it.” 
Another interviewee also stated that the judge played an important role in explaining and educating the court about the effects of trauma on an individual's ability to parent, The judge went a long way to talk about the fact that most of the grown ups had probably suffered the trauma, and that that would affect their ability to parent...We have little impromptu meetings when there's some down time. The judge will say, well, what do you think about this? What do you think about that? And I think that's where the judicial education is important too, and getting feedback, consistently getting feedback which will make it a better, it will make everyone feel like their voice is being heard and also maybe improvements can be made, and so I think that would be a great way to contribute to the whole, trauma-informed [systems change]

\section{DISCUSSION}

This study explored insights from key professionals working in the fields of substance abuse, mental health, child welfare, and the courts around their experience implementing traumainformed systems change in a collaborative FDTC setting. Results of the study describe the benefits and barriers to assessing and addressing the need for trauma-informed systems change in a collaborative context. Responses from key informers demonstrated the relevance of traumainformed systems change in collaborative contexts, such as family drug treatment courts, designed to address the complex needs of children and families.

Analysis of historical documents and interview narratives revealed a number of potential trauma "triggers" as well as strategies for reducing triggers, which may be relevant to practice across contexts (e.g. creating opportunities for client choice, rather than mandating specific treatment options). Findings from in-depth interviews underscore the importance of a wide variety of systems players (e.g. court, addiction services, child welfare, mental health) embracing 
a process of trauma-informed assessment and systems improvement in a planned, collaborative process that has as its core value to better address the needs of vulnerable families. The emphasis on development of shared values and adoption of specific systems level changes across systems is consistent with literature describing successful collaborative practice between dependency courts, child welfare, addiction treatment and allied fields (Young \& Gardner, 2002). Findings are also consistent with studies emphasizing the importance of strategic efforts for implementing system-wide changes in practice, engagement of multiple stakeholders, and shared governance (Elliot et. al, 2005; Mildon \& Shlonsky, 2011: Reed \& Mazelis, 2005).

\section{Study Limitations}

This study has a number of limitations. Although this study obtained a sample of crosssystems partners and program representatives affiliated with one FDTC, a relatively small sample size of twelve interviewees limits the generalizability of the findings in other contexts. The sample included primarily leaders and other stakeholders who were highly involved in the FDTC and did not include a breadth of representatives from each partner system; consequently, findings may not be reflective of the perspectives of other leaders and line staff throughout different service delivery systems. Additional research would be needed to examine the degree to which trauma-informed systems change efforts penetrate and influence the perspectives and practices of leaders and providers throughout partner systems. In addition, purposive sampling was made possible with the help of key informants in the courts familiar with and integrated in trauma-informed systems change. Although historical documents were triangulated with interview data and a member-check process was implemented to strengthen trustworthiness and credibility of the findings, biases of the researchers and key informers have the potential to skew conclusions that may be drawn from this study. 


\section{Conclusion}

The current study demonstrates the impact of trauma-informed systems change initiatives in collaborative FDTCs and underscores the need for further inquiry and research in this area. In particular, there is a need for research documenting the implementation and outcomes of traumainformed efforts in dependency court contexts, and other courts serving individuals with histories of trauma. There is also a need for research specifically examining outcomes for clients, particularly in regard to reunification and recovery, when courts are trauma-informed. Finally, it will be important that future research examine how addressing the issue of trauma among parents may impact children, particularly in children with histories of trauma, victimization, abuse, and removal from their parents. This future research will be particularly salient for understanding effective strategies at preparing children and families in the child welfare system for successful reunification.

Assessment tools, such as the trauma-informed systems walk-through, are important for organizational and service delivery improvement. They can demonstrate the impact of minimal cost activities on informing systems and services change. Cost neutral or minimal cost processes have exceptional value in the human services field, especially considering the current fiscal climate, in identifying small, do-able changes as a strategy for service improvement.

Collaborative process is a hallmark of social work practice. Advancing systems assessment processes and change efforts are valuable to fostering effective cross-systems collaboration, clarifying shared values, and developing a framework for congruent practice. According to Elliot et al. (2005), formal collaboration is especially critical in reducing trauma for consumers. FDTCs, in particular, interact with multiple systems players while addressing a multitude of complex problems, such as addiction, mental health, health, family violence, and 
child abuse. Therefore, implementing trauma-informed systems change in collaborative contexts, like FDTCs, has the potential for positive impact in practice, programming, and policy across these multiple systems. Finally, implementing trauma-informed systems change has the potential to greatly impact outcomes for clients, including their experience of different systems and faith in the recovery process. 


\section{References}

Amaro, H., Chernoff, M., Brown, V., Arévalo, S., \& Gatz, M. (2007). Does Integrated TraumaInformed Substance Abuse Treatment Increase Treatment Retention? Journal of Community Psychology, 35(7), 845-862.

Becker M. A., Noether C. D., Larson M. J., Gatz M., Brown V., Heckman J. P., \& Giard J. (2005). Characteristics of women engaged in treatment for trauma and co-occurring disorders: Findings from a national multisite study. Journal of Community Psychology, 33(4), 429-443.

Bloom, S. L. (2006). Trauma-informed systems transformation: Recovery as a public health concern. Report for the Trauma Task Force, Philadelphia, PA. Retrieved from http://www.sanctuaryweb.com/publications.php

Boles, S. M., Young, N. K., Moore, T., \& DiPirro-Beard, S. (2007). The Sacramento Dependency Drug Court: Development and outcomes. Child Maltreatment, 12(2), 161171.

British Columbia Center of Excellence for Women’s Health (BCCEWH, 2011). Coalescing on women and substance use: Assisting women with mental health, substance use and trauma-related concerns through trauma-informed approaches. Trauma-informed approaches online tool 1.0. Retrieved from http://www.coalescing-vc.org/virtual Learning/documents/trauma-informed-online-tool.pdf

Brosky, B. A. \& Lally, S. J. (2004). Prevalence of trauma, PTSD, and dissociation in courtreferred adolescents. Journal of Interpersonal Violence, 19(7), 801-814.

Bryer, J., Nelson, B., Miller, J., \& Krol, P. (1987). Childhood physical and sexual abuse as factors in adult psychiatric illness. American Journal of Psychiatry, 144, 1426-1430. 
Buel, S. M. (2003). Addressing family violence within juvenile courts: Promising practices to improve intervention outcomes. Journal of Aggression, Maltreatment \& Trauma, 8(3), $17,273-307$.

Carlson, B. E. (2006). Best Practices in the Treatment of Substance-Abusing Women in the Child Welfare System. Journal of Social Work Practice in the Addictions, 6(3), 97-115.

Drabble, L. (2011). Advancing Collaborative Practice Between Substance Abuse Treatment and Child Welfare Fields: What Helps and Hinders the Process? Administration in Social Work, 35(1), 88-106.

Dube, S. R., Felitti, V. J., Dong, M., Giles, W. H., \& Anda, R. F. (2003). The impact of adverse childhood experiences on health problems: Evidence from four birth cohorts dating back to 1900. Preventative Medicine, 37, 268-277.

Edwards, L. P. \& Ray, J. A. (2005). Judicial perspectives on family drug treatment courts. Juvenile and Family Court Journal, 56(3) 1-27.

Elliott, D. E., Bjelajac, P., Fallot, R. D., Markoff, L. S., \& Reed, B.G. (2005). Trauma-informed or trauma-denied: Principles and implementation of trauma-informed services for women. Journal of Community Psychology, 33(4), 429-443.

Fallot, R. D., \& Harris, M. (2006, March). Trauma-informed services: A self-assessment and Planning Protocol. Washington, DC: Community Connections.

Felitti V. J., Anda R. F., Nordenberg D., Williamson D. F., Spitz A. M., Edwards V., Koss M. P., \& Marks J. S. (1998). Relationship of childhood abuse and household dysfunction to many of the leading causes of death in adults: The adverse childhood experiences (ACE) study. American Journal of Preventative Medicine, 14(4), 245-258. 
Green, B. L., Rockhill, A., \& Furrer, C. (2006). Understanding patterns of substance abuse treatment for women involved with child welfare: The influence of the Adoption and Safe Families Act (ASFA). The American Journal of Drug and Alcohol Abuse, 32(2), 149-176. doi: 10.1080/00952990500479282

Green, B. L., Furrer, C., Worcel, S., Burrus, S., \& Finigan, M. W. (2007). How effective are family treatment drug courts? Outcomes from a four-site national study. Child Maltreatment, 12(1), 43-59. doi: 10.1177/1077559506296317

Green, B. L., Rockhill, A., \& Burrus, S. (2008). The role of interagency collaboration for substance-abusing families involved in child welfare. Child Welfare, 87(1), 29-61.

Harris M. and Fallot, R. (Eds.). (2001). Using trauma theory to design service systems. San Francisco, CA: Jossey-Bass.

Hodas, G. R. (2006). Responding to childhood trauma: The promise and practice of traumainformed care. Pennsylvania Office of Mental Health and Substance Abuse Services. Retrieved from http://www.childrescuebill.org/VictimsOfAbuse/RespondingHodas.pdf

Kilpatrick, D., Acierno, R., Resnick, H., Saunders, B., \& Best, C. (1997). A 2-year longitudinal analysis of the relationships between violence and substance abuse in women. Journal of Consulting and Clinical Psychology, 65, 834-857.

Ko, S.J., Ford, J.D., Kassam-Adams, N., Berkowitz, S.J., Wilson, C., Wong, M., Brymer, M.J., Layne, C.M. (2008). Creating trauma-informed systems: Child welfare, education, first responders, health care, juvenile justice. Professional Psychology: Research and Practice, 39, (4), 396-404.

Lesperance, T., Moore, K. A., Barrett, B., Young, M. S., Clark, C., \& Ochshorn, E. (2001). Relationship between trauma and risky behavior in substance abusing parents involved in 
family dependency treatment court. Journal of Aggression, Maltreatment, and Trauma, 20(2), 163-174. doi: 10.1080/10926771.2011.546752

Marsh, J. C., Smith, B. D., \& Bruni, M. (2010). Integrated substance abuse and child welfare services for women: A progress review. Children and Youth Services Review, 33(3):466472.

McHugo, G. J., Caspi, Y., Kammerer, N., Mazelis, R., Jackson, E. W., Russell, L., Clark C., Liebschutz, J., \& Kimerling, R. (2005). The assessment of trauma history in women with co-occurring substance abuse and mental disorders and a history of interpersonal violence. Journal of Behavioral Health Services and Research, 32(2), 113-l27.

McHugo, G. J., Kammerer, N., Jackson, E. W., Markoff, L. S., Gatz, M., Larson, M. J., Mazelis, R., \& Hennigan, K. (2005). Women, co-occurring disorders, and violence study: Evaluation design and study population. Journal of Substance Abuse Treatment, 28, 91107.

Mildon, R., \& Shlonsky, A. (2011). Bridge over troubled water: Using implementation science to facilitate effective services in child welfare. Child Abuse \& Neglect, 35(9), 753-756.

Morrissey, J. P., Ellis, A. R., Gatz, M., Amaro, H., Reed B. G., Savage, A., Finkelstein, N., Mazelis R., Brown, V., Jackson, E. W., \& Banks, S. (2005). Outcomes for women with co-occurring disorders and trauma: Program and person-level effects. Journal of Substance Abuse Treatment, 28, 121-133.

Morrissey, J. P., Jackson, E. W., Ellis, A. R., Amaro, H., Brown, V. B., Najavits, L. M. (2005). Twelve-month outcomes of trauma-informed interventions for women with co-occurring disorders. Psychiatric Services, 56(10), 1213-1222.

Najavits, L. M., Weiss, R. D., \& Shaw, S. R. (1997). The link between substance abuse and 
posttraumatic stress disorder in women: A research review. American Journal on Addictions, 6(4), 273-283.

National Association of State Mental Health Program Directors (NASMHPD) and National Technical Assistance Center for State Mental Health Planning (NTAC) (2004): The damaging consequences of violence and trauma: Facts, discussion points, and recommendations for the behavioral health system. Washington, D.C.: U.S. Department of Health and Human Services (HHS).

National Center for Injury Prevention and Control (2005): Child maltreatment: Overview www.cdc.gov/ncipc/factsheets/cmoverview.htm, and Child maltreatment: Prevention strategies, www.cdc.gov/ncipc/factsheets/cmpreverntion.htm.

Osterling, K. L., \& Austin, M. J. (2008). Substance abuse interventions for parents involved in the child welfare system: Evidence and implications. Journal of Evidence-Based Social Work, 5(1/2), 157-189.

Reed, B. \& Mazelis, R. (2005). Scholarship, collaboration, struggle, and learning in the women, co-occurring disorders, and violence study: Introduction to the 6-month outcome. Journal of Substance Abuse Treatment, 28, 87-89.

Ryan, J. P., Marsh, J., C., Testa, M. F., \& Louderman, R. (2006). Integrating substance abuse treatment and child welfare services: Findings from the Illinois alcohol and other drug abuse waiver demonstration. Social Work Research, 30(2), 95-107.

Savage A., Quiros, L., Dodd S. J., Bonavota, D. (2007). Building trauma-informed practice: Appreciating the impact of trauma in the lives of women with substance abuse and mental health problems. Journal of Social Work Practice in the Addictions, 7, 91-116. 
Strauss, A. L. (1987). Qualitative analysis for social services. Cambridge: Cambridge University Press.

Strauss, A. L., \& Corbin, J. (1990). Basics of qualitative research: Grounded theory procedures and techniques. Newbury Park, CA: Sage.

Timko, C., \& Moos, R.H. (2002). Symptom severity, amount of treatment, and 1-year outcomes among dual diagnosis patients. Administration and Policy in Mental Health, 30, 35-54.

U. S. Department of Health and Human Services, Administration for Children and Families, (1997). Adoption and Safe Families Act of 1997. Retrieved from http://www.acf.hhs.gov/ programs/cb/laws_policies/cblaws/public_law/pl105_89/pl105_89.htm

U.S. Department of Health and Human Services. (2010). Targeted grants to increase the well-being of, and to improve the permanency outcomes for, children affected by methamphetamine or other substance abuse: First annual report to congress. Washington, D.C.: U.S. Department of Health and Human Services, Administration for Children and Families, Administration on Children, Youth and Families, Children's Bureau. Retreived from: http://www.acf.hhs.gov/programs/cb/pubs/targeted_grants/targeted_grants.pdf

U.S. Department of Health and Human Services. (1999). Blending perspectives and building common ground: A report to congress on substance abuse and child protection. U.S. Government Printing Office: Washington, D.C. Retrieved from aspe.hhs.gov/hsp/ subabuse99/subabuse.htm

Worcel, S. D., Furrer, C. J., Green, B. L., Burrus, S. W. M., \& Finigan, M. W. (2008). Effects of family treatment drug courts on substance abuse and child welfare outcomes. [Article]. Child Abuse Review, 17(6), 427-443. 
Young, N. K., Boles, S. M., \& Otero, C. (2007). Parental substance use disorders and child maltreatment: Overlap, gaps, and opportunities. Child Maltreatment, 12(2), 137-149.

Young, N. K., \& Gardner, S. (2002). Navigating the pathways: Lessons and promising practices in linking alcohol and drug services with child welfare. SAMHSA Publication No. SMA02-3639. Rockville, MD: Center for Substance Abuse Treatment, Substance Abuse and Mental Health Services Administration. 
Figure 1: Benefits, Barriers and Facilitating Factors in Advancing Trauma-Informed Systems Change

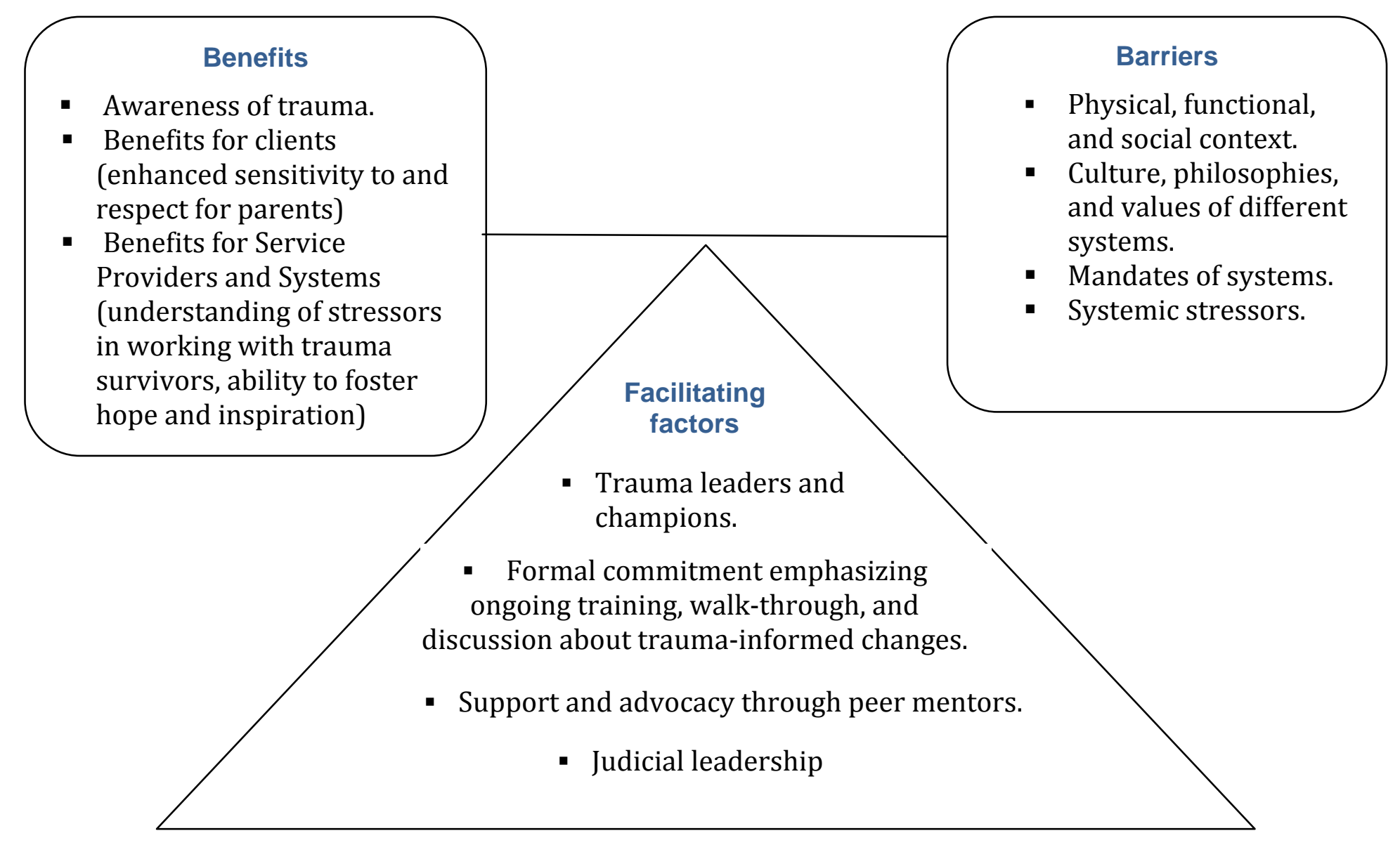

